\title{
Hydroxyapatite and Demineralized Bone Matrix from Marine Food Waste - A Possible Bone Implant
}

\author{
Rethinam Senthil ${ }^{1, *}$, Sathyaraj Weslen Vedakumari ${ }^{2}$, Thotapalli Parvathaleswara Sastry ${ }^{1}$ \\ ${ }^{1}$ Biological Materials Lab, Central Leather Research Institute, Chennai, India \\ ${ }^{2}$ Faculty of Allied Health Science, Chettinad Academy of Research \& Education, Chennai, India
}

Email address:

senthilbiop@gmail.com (R. Senthil), rethinam.senthil@gmail.com (R. Senthil)

${ }^{*}$ Corresponding author

To cite this article:

Rethinam Senthil, Sathyaraj Weslen Vedakumari, Thotapalli Parvathaleswara Sastry. Hydroxyapatite and Demineralized Bone Matrix from Marine Food Waste - A Possible Bone Implant. American Journal of Materials Synthesis and Processing. Vol. 3, No. 1, 2018 , pp. 1-6. doi: 10.11648/j.ajmsp.20180301.11

Received: September 28, 2017; Accepted: October 18, 2017; Published: January 18, 2018

\begin{abstract}
In the present study, a novel bone implant (BI) was prepared using demineralized bone matrix (DBM) and hydroxyapatite (HA) isolated from Bluefin trevally (BT) bones, which was considered to be a marine industry food waste. Gelatin (GA) was used as a binder. Physico-chemical characterization and in vitro studies were carried out using this implant. Fourier transform infrared spectrum of BI exhibited the characteristic bands of all the three components viz., DBM, HA and GA, while scanning electron microscopic studies revealed the irregular shape of the particles. The mechanical properties of BI were also appreciable. In vitro studies were carried out using Human keratinocyte cell line (HaCaT), wherein MTT (3-(4,5dimethylazol-2-yl)-2,5-diphenyl-tetrazolium bromide) assay proved the biocompatibility of BI. From the results obtained it could be stated that BI prepared from waste marine bones could serve as a promising biomaterial for bone tissue engineering applications.
\end{abstract}

Keywords: Fish Waste, Recycling, Bone Implant, Biomaterial

\section{Introduction}

Fish bone, a by-product of the marine food product industries is an organic solid waste, which needs proper disposal [1]. Bluefin trevally (BT) fishes used for fillet production and large quantity of bone are being discarded as waste. The enormous volumes of these materials are not utilized, but a create disposal problem in the environmental pollution [2]. The marine food product industries waste for making biomaterial of higher value [3]. Many treated fish waste products have been developed for various purposes are animal feed, biodiesel/biogas, chitosan, natural pigments, collagen and bone implant [4].

Bone tissue engineering based on clinical applications in bone replacement, bone neoplasia and tumors, maxillofacial, craniofacial, orthopedic, neck and head surgery [5]. Natural or synthetic polymers, human bones, corals, coral derivatives, animal bones, synthetic ceramics, and composites are currently used as commercial substitutes to replace or repair bone and teeth [6]. Manjubala et al [7] have reported that recovering osteoconduction and osteoinduction, an association of extracellular matrix scaffolds with osteogenic cells, growth and differentiation factors may be required.

Hydroxyapatite $\left[\mathrm{Ca}_{10}\left(\mathrm{PO}_{4}\right)_{6}(\mathrm{OH})_{2}\right]$ used for various therapeutic fields, its good biocompatibility, bioactivity, high osteoconductive and osteoinductive, nontoxicity, noninflammatory behavior and nonimmunogenicity properties [8]. Hydroxyapatite (HA) synthesis was used to different production methods were reported such as sol-gel, chemical precipitation, hydrothermal technique, electrodeposition technique, multiple emulsion technique etc [9].

Hydroxyapatite (HA) widely used as bone graft material such as biomedical and dental applications. Calcium phosphate bio ceramics viz., calcium phosphate, tri-calcium phosphate and hydroxyapatite are most suitable bone substitution materials [10]. Demineralized bone matrix (DBM) commonly used bone-graft replacement material [11, 
12]. The bone mineral are rich in HA and the bone protein is mainly composed of collagen. Collagen acts as a structural framework in which plate-like small crystal of HA are embedded to strengthen the bone [13].

The objective of this study was to prepare a bone implant (BI) from fish bone wastes. The prepared BI was characterized for its physicochemical properties using Fourier transform infrared, X-ray diffractometry, thermogravimetric analysis and scanning electron microscopy. In vitro studies were carried out using Human keratinocyte cell line (HaCaT) to assess the biocompatibility of BI.

\section{Materials and Methods}

\subsection{Synthesis of Hydroxyapatite (HA) Powder from Fish Bone Waste}

$500 \mathrm{~g}$ of fish bone wastes were collected from Poombukar boating harbour, Tamilnadu, India and were cut into $2 \times 2$ inch pieces using a prebreaker. The bone pieces were incinerated at $300^{\circ} \mathrm{C}$ for $3 \mathrm{~h}$. The samples were further ashed at $750^{\circ} \mathrm{C}$ for about $5 \mathrm{~h}$ using muffle furnace. The ashed samples were crushed to form a fine powder using a mortar/pestle.

\subsection{Preparation of Demineralised Bone Matrix (DBM)}

The crushed bones of BT were washed thoroughly in distilled water and defatted using acetone: chloroform in the ratio $3: 1$ for $12 \mathrm{~h}$. The defatted bones were acid extraction using $2 \mathrm{~N} \mathrm{HCI}$ (The solution was changed daily) for 7 days at $4^{\circ} \mathrm{C}$. pH was maintained at 7 and the resulting soft bone was grinded and dried under shade at $30^{\circ} \mathrm{C}$ for $12 \mathrm{~h}$. The dried samples were stored at about $20^{\circ} \mathrm{C}$ till further use. It is denoted as DBM.

\subsection{Preparation of Bone Implant (BI)}

Bone implant (BI) was prepared according to the method of [14]. BI was prepared by mixing HA: DBM and GA in the ratio of $65 \%: 25 \%: 10 \%$ and the resultant mixture was packed into the glass tube (size $10 \mathrm{~mm}$ diameter) and extruded out with a suitable glass rod. The cylindrical implants formed were cut into required length and cure at $30^{\circ} \mathrm{C}$ for 2 to $3 \mathrm{~h}$. The prepared bone implant was dried at $55^{\circ} \mathrm{C}$ overnight and finally at $100^{\circ} \mathrm{C}$ for $4 \mathrm{~h}$. The dried implant were sealed and stored in polythene covers for further use.

\subsection{Preparation of Simulated Body Fluid (SBF)}

The growth medium of simulated body fluid (SBF) was prepared using chemical grade $\mathrm{NaCl}(7.995 \mathrm{~g}), \mathrm{NaHCO}_{3}$ $(0.353 \mathrm{~g}), \quad \mathrm{KCl}(0.224 \mathrm{~g}), \mathrm{K}_{2} \mathrm{HPO}_{4} \cdot 3 \mathrm{H}_{2} \mathrm{O} \quad(0 \cdot 228 \mathrm{~g})$, $\mathrm{MgCl} .6 \mathrm{H}_{2} \mathrm{O}(0 \cdot 305 \mathrm{~g}), \mathrm{CaCl}_{2}(0 \cdot 227 \mathrm{~g})$ and $\mathrm{Na}_{2} \mathrm{SO}_{4}(0 \cdot 0710 \mathrm{~g})$ in $1 \mathrm{~L}$ of deionized water. The prepared solution was buffered at $\mathrm{pH} 7.4$ with tris (hydroxyl methyl) amino methane $\left(\mathrm{CH}_{2} \mathrm{OH}\right)$ and $1 \mathrm{M}$ hydrochloric acid (HCL) at $37^{\circ} \mathrm{C}[15]$.

\subsection{Preparation of Bone Implant (BII)}

The bone implant $(1.5 \mathrm{~mm}$ diameter $\times 3 \mathrm{~cm}$ length $)$ was soaked in $20 \mathrm{~mL}$ of SBF solution for 21 days. The SBF solution was refreshed in every two days to maintain $\mathrm{pH}$ level and avoid microbial contamination. After 21 days of soaked sample, the BI was removed from SBF solution and vacuum dried at $45^{\circ} \mathrm{C}$ for $24 \mathrm{~h}$.

\subsection{Physico-Chemical Characterization}

Fourier transform infrared (FTIR) spectroscopy measurements were carried out to determine the formation and changes in the functional groups of the individual component in BI. The spectra were measured at a resolution of $4 \mathrm{~cm}^{-1}$ in the frequency range of $4000-500 \mathrm{~cm}^{-1}$ using Nicolet 360 . Crystal structure and phase composition of bone graft were detected using X-ray diffractometer. (Bruker D8 ADVANCE) with $\mathrm{Cu} \mathrm{K} \alpha(\lambda=0.1548 \mathrm{~nm})$ radiation in the $2 \theta$ scan ranged from $2^{\circ}$ to $90^{\circ}$ at a scan rate of $1 \% \mathrm{~min}$. The thermo gravimetric analysis (TGA) of the prepared scaffolds was carried out using a Seiko SSC $5200 \mathrm{H}$ thermal analysis in nitrogen atmosphere $(80 \mathrm{~mL} / \mathrm{min})$ at a heating rate of $10{ }^{\circ} \mathrm{C} / \mathrm{min}$. Primary weight loss of these materials as a function of temperature was recorded using this study. The surface morphology of the samples before and after in vitro bio-mineralization assay was visualized using scanning electron microscope (SEM) (SEM Model LEICA stereo scan 440). The samples were coated with gold ions using an ion coater (Fisons sputter coater) 0.1 Torr pressure, $20 \mathrm{~mA}$ current and $15 \mathrm{kV}$ accelerating voltage for 70 seconds.

The porosities of the samples HA, BI and BI1 were determined using the method according to Zhang et al [16]. Briefly, known weights of the each sample were soaked in known of ethanol for $5 \mathrm{~min}$ and then a series of brief evacuation- depressurization cycles were conducted to force the ethanol into the pores of the samples. The process was repeated until the air bubbles stops. The samples were removed after total volume of the ethanol and the ethanol impregnated samples was assessed.

The percent porosity was calculated using following equation

$$
\text { Porosity }(\%)=\left[1-\frac{W \mathrm{w}-W \mathrm{~d}}{\mathrm{SV}}\right] \times 100
$$

Where SV is the sample volume $W_{\mathrm{W}}$ and $W \mathrm{~d}$ are the wet and initial dry weights of the sample, respectively.

Mechanical properties were analysed using specimens of 4 $\mathrm{mm}$ wide and $10 \mathrm{~mm}$ length. Compressive strength was measured using INSTRON (model 4501) at a speed rate of $1 \mathrm{~mm} / \mathrm{min}$. Tensile strength (Mpa) was measured using INSTRON (model 4501) at an extension rate of $5 \mathrm{~mm} / \mathrm{min}$.

\subsection{MTT (3-(4, 5-dimethylazol-2-yl)-2,5- diphenyltetrazolium Bromide) Assay}

Biocompatibility study was performed on Human keratinocyte cell line (HaCaT) obtained from National Centre for Cell Science (NCCS), Pune, India. The cells were maintained in Dulbecco' Modified Eagles Medium and supplemented with $10 \%$ fetal bovine serum (FBS) at $37^{\circ} \mathrm{C}$, 
$95 \%$ air and $5 \% \mathrm{CO}_{2}$. Cell viability activity was evaluated calorimetrically by MTT (3-(4, 5-dimethylazol-2-yl)-2,5diphenyltetrazolium bromide) assay. Cells $\left(25 \times 10_{3}\right.$ cells $\left./ \mathrm{mL}\right)$ were seeded on sample in a 24 -well plate. After 30 minutes, $10 \%$ medium was added and the cells were incubated for 1,3 and 5 days. At the end of the incubation period, MTT was added and the plates were incubated for $4 \mathrm{~h}$ at $37^{\circ} \mathrm{C}$. Following incubation, the media was aspirated completely and MTT formazon crystals formed were dissolved by the addition of dimethylsulfoxide, and the reading was taken at $570 \mathrm{~nm}$ using Spectra Max M4. The cell growth on the culture plate without sample was taken as controls. The percentage of cells viability was calculated compared to the control. The cells morphology was viewed using inverted microscope [17].

\subsection{Statistical Analysis}

Results are presented as mean \pm standard deviation (SD) of three individual experiments $(n=3)$. ANOVA (Analysis of variance) and Duncan's multiple range analysis were done to determine the significant differences among the groups. $p$ values of $\mathrm{p}<0.05$ were considered significant.

\section{Results and Discussion}

Preparation of bone implant using marine food waste would result in low cost bone implant with higher strength. Bio-compatible biopolymers are incorporated in these materials to enable good quality bone implant material for its appropriate usage in the orthopaedic medical field. The prepared bone implant shows biochemical characteristic required for the application of bone implant.

\subsection{Physico-Chemical Characterization}

FTIR spectrum was used to study the functional groups of the samples. The FTIR spectra of HA (Figure 1a), O-H stretching peak at $5372 \mathrm{~cm}^{-1}$ which confirm the presence of hydroxyapatite. FTIR spectrum of BI (Figure 1b) has shown characteristic bands of phosphate and hydroxyl group of HA, GA and DBM, the hydroxyl group of gelatine exhibited peaks at $1658 \mathrm{~cm}^{-1}$ and $1552 \mathrm{~cm}^{-1}$. The peak of the tetrahedral orthophosphate group was observed at $564 \mathrm{~cm}^{-1}$. In addition, BI1 (Figure 1c) exhibits amide I and II absorption bands at $1662 \mathrm{~cm}^{-1}$ and $1550 \mathrm{~cm}^{-1}$, respectively and contains all the characteristic absorption peaks at HA, GA and DBM. XRD patterns of HA, BI and BI1 (Figure 2 (ac)) showed a peak in the range of $31.8-32.50$ of $2 \theta$ values, which corresponds to the characteristic peak of apatite phase. The spectrum of BI exhibits the diffraction peaks at $2 \theta$ values which confirm the crystalline nature of HA, GA and DBM in the sample. The XRD spectra of BI1 shows $2 \theta$ values $19^{\circ}$ broadening of the apatite peaks with decrease in crystallinity of HA.
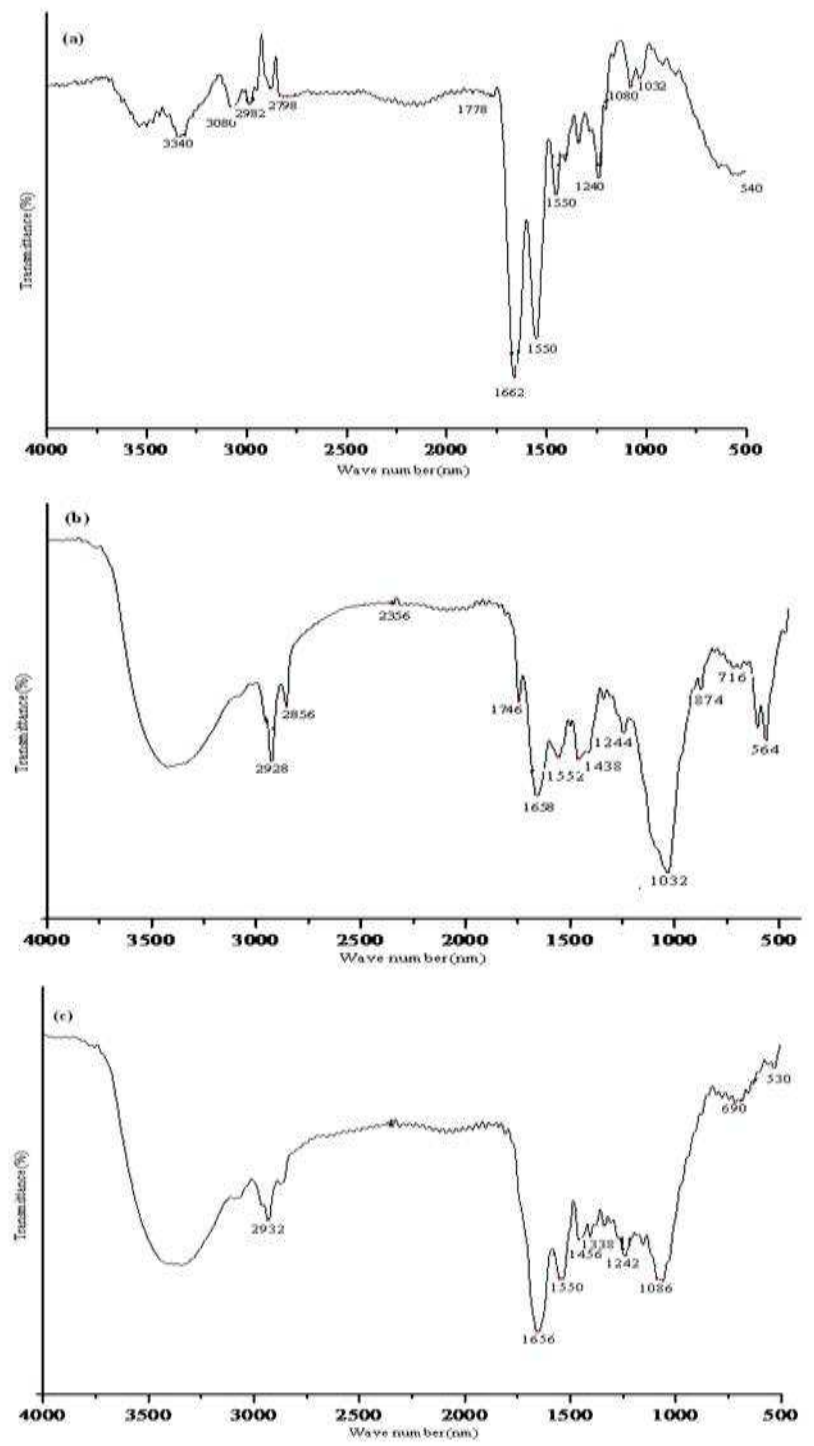

Figure 1. FTIR spectra of (a) HA (b) BI (c) BII.

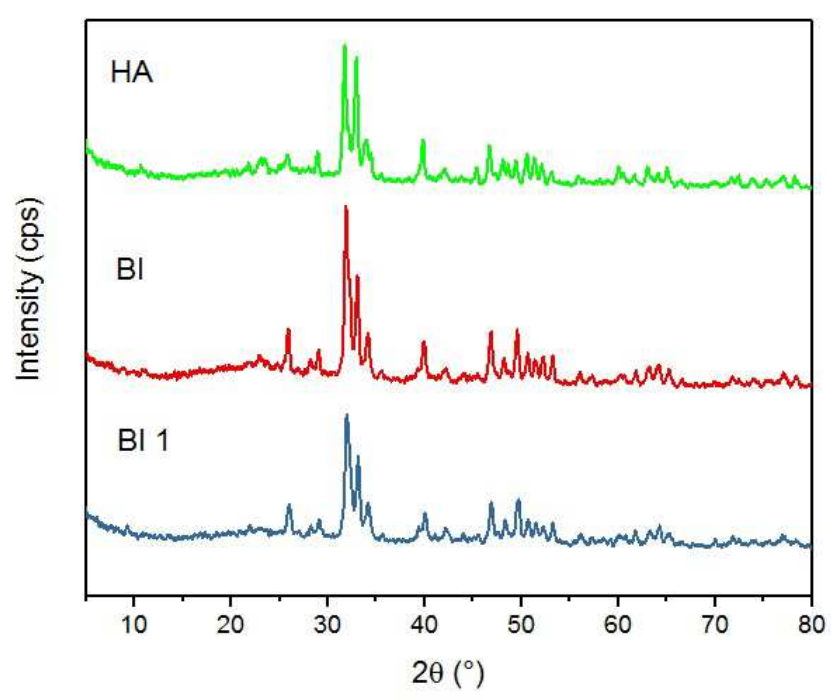




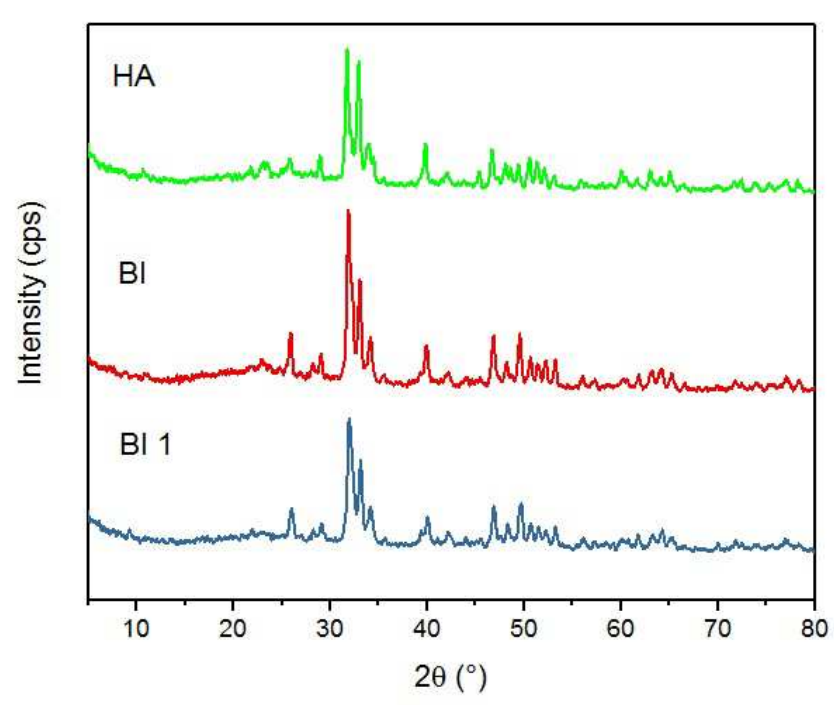

Figure 2. XRD of (a) $H A$ (b) $B I$ (c) BII.

Jianguo et al [18] reported that orthophosphate and carbonate group were present in all kinds of bone materials. The amide I characteristic frequencies broadband range from 1,600 to $1,700 \mathrm{~cm}^{-1}$ of the carbonyl group $(\mathrm{C}=\mathrm{O}$ bond $)$ and amide II wave number $1551 \mathrm{~cm}^{-1}$ [19]. The XRD values were found compared to standard HA in the case previously reported by Ucker et al [20]. The weight loss between 300 to $600^{\circ} \mathrm{C}$ could be due to the degradation of organic compounds in the composite and after treatment in SBF into intermediate compounds. The thermal degradation temperature of collagen was between 200 to $440^{\circ} \mathrm{C}$ [21]. The weight loss at 600 to $1200^{\circ} \mathrm{C}$ can be ascribed to the degradation of bone implant material as reported by Das et al [22].

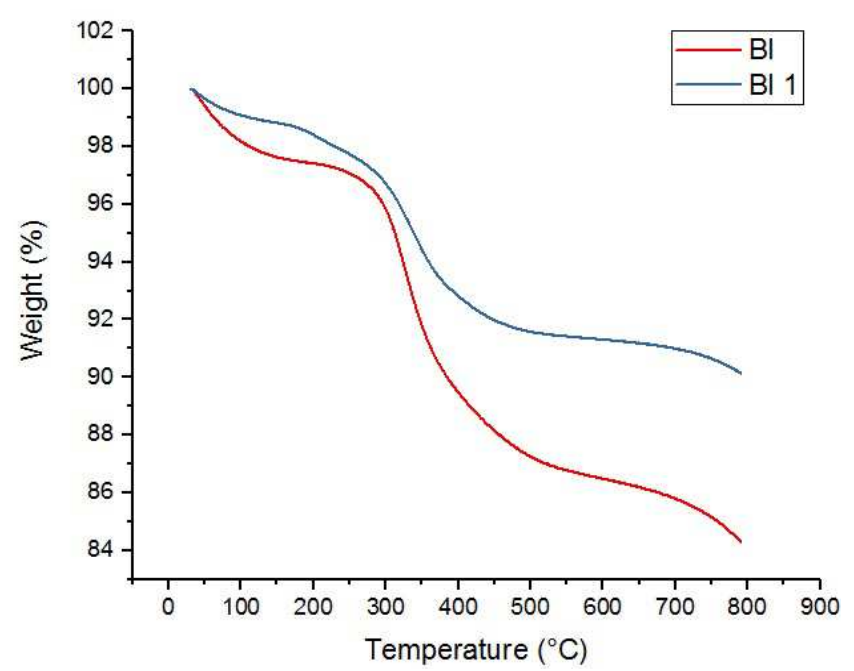

Figure 3. TGA analysis of (a) BI (b) BII.

TGA of BI and BI1 are shown in (Figure 3a \& b) respectively. BI (Figure 3a), weight loss was recorded in 708 and $90.14 \%$ remained as final residue. The major weight loss between 166 to $708^{\circ} \mathrm{C}$ could be due to the decomposition of gelatine. Similarly BI1 (Figure 3b) observed initial weight loss of about $6 \%$ at $218^{\circ} \mathrm{C}$ and final weight loss of about $6 \%$ at $724^{\circ} \mathrm{C}$ and $85 \%$ as final residue. In both the cases, the initial weight loss is due to the evaporation of water molecules in the samples and the final weight loss is due to the denaturation of protein present in BI and BI1 respectively.

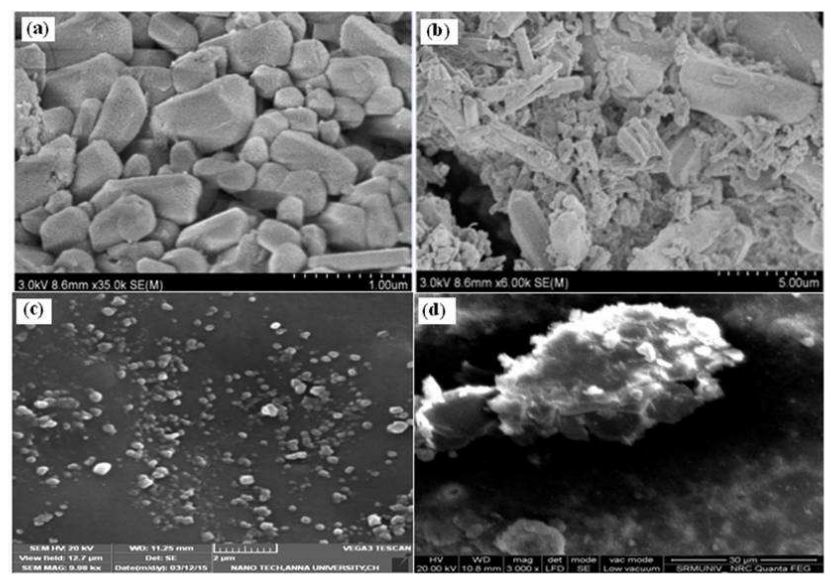

Figure 4. SEM images of (a) DBM (b) HA particles (c) BI (d) BII.

The surface morphology of DBM, HA, BI and BI1 was studied using SEM. The SEM picture of DBM was observed in spherical size (Figure 4a). Figure 4b showed HA powder exhibited irregular shapes. Figure. $4 \mathrm{c}$ seen at $\mathrm{BI}$ as fine particles of HA dispersed well in GA. The images revealed proper binding of GA by HA and DBM. Figure 4d SEM images clearly indicate mineralization of BI in SBF solution and revealed the increase in calcium and phosphate contents in the composite with SBF treatment compared to those of without treatment, this is due to deposition of calcium and phosphate onto composite treated in SBF. The porosity observed of HA, BI and BI1 are shown in Figure 5. The results exhibited that the water absorption of the samples for using tissue engineering application. BI1 which showed more porous in nature with a smoother surface compared to HA and BI. It was conformed BI1 sample pore size were well dispersed. The BI possessed compressive strength of about $4.56 \pm 0.26 \mathrm{Mpa}$ and $18.51 \pm 0.07 \mathrm{Mpa}$ as tensile strength. It is clearly evident from the results, that BI1 possessed better mechanical properties, which may find applications in the manufacture of bone implant.

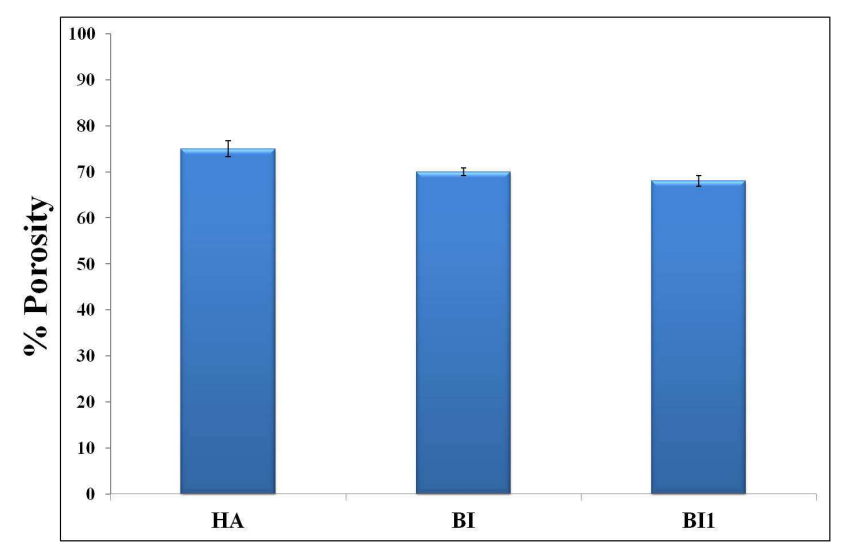

Figure 5. Showing the porosity of $H A, B I, B I 1$. 
Previous studies that prepared bone implant using SEM analysis was indicated rough porous surface, density, cell adhesion [23]. The bone implants were of suitable size and highly porous to provide an optimal environment for new bone regeneration [24]. Boskey [25] reported the mineralized bone matrix and their morphologies, ultra structure and biochemical characteristics. Mbarki et al [26] reported the calcium based bone implant could be used specific properties such as porosity, density, tensile strength and compressive strength. Liu and Fh [27] stated that suitable bone scaffold material could be using laser sintering technology in 3D printing technology with tensile strength $14.1 \mathrm{MPa}$ and three point fracture strength of this composite value of tensile strength $24 \mathrm{Mpa}$.

\subsection{MTT (3-(4, 5-dimethylazol-2-yl)-2,5- diphenyltetrazolium Bromide) Assay}

The biocompatibility of BI1 was evaluated using MTT assay, which is low cost to determine the toxicity exerted by the biomaterials. Figure $6 a$ observed the viability of the human keratinocyte cell line in the presence of BI1 for 1, 2 and 3 days, respectively. To examine the results showed that the proliferation of $\mathrm{HaCaT}$ cells was more significantly increased on BI1 treated samples compared to control. The morphology of the HaCaT cells that adhered on the BI1 was assessed through inverted microscopy, as shown in Figure 6b. The results suggest that where BI1 is used as bone implant no toxic substance will be released by the processes bone and as well as no chemical residue.

(a)
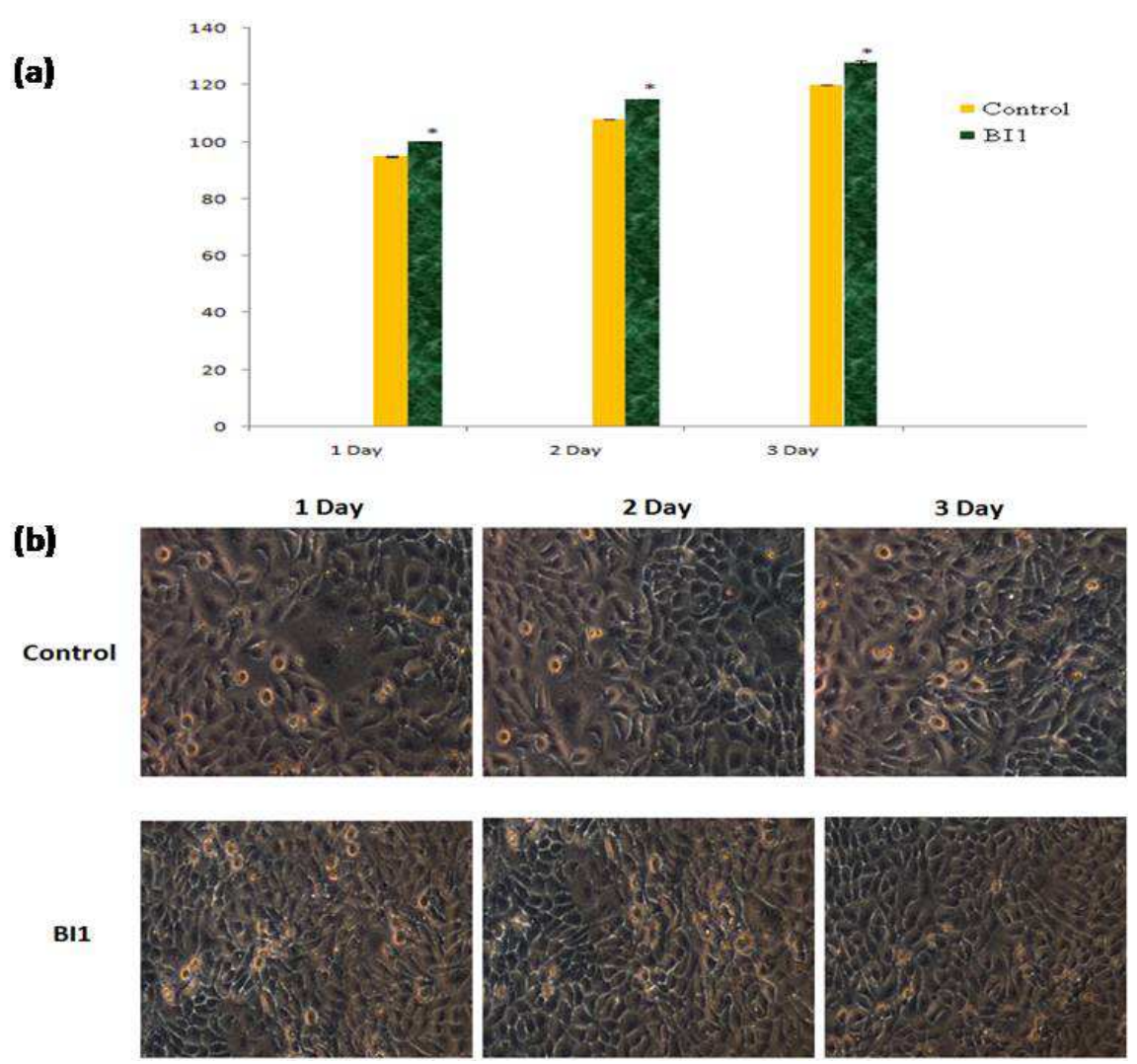

Figure 6. In vitro studies (a) MTT assay representation of BI1 on Human keratinocyte cells. The asterisks (*) indicate statistically significant differences compared to the control $p<0.05$ (b) Phase contrast micrographs (20×) of Human keratinocyte cells culture on day 1 , day 2 and day 3.

Evaluating MTT assay is an effective method of assessing biocompatible, cell attachment and proliferation [28, 29]. From the results showed no cytotoxic and good biocompatibility, growth and proliferation of HaCaT cells. $\mathrm{HaCaT}$ cells were well distributed on the BI1 and there was no statistically significant differences between control and BI1 treated group. Calcium and phosphate serve as nucleating agents for the formation of hydroxyapatite, a main component of bone [30].

\section{Conclusion}

Preparation of bone implant from fish bone is an attempt towards cost effective materials. Also, since the fish bone used in the bone implant is derived from marine food waste materials, it possesses an environmental significant as well. Since the bone implant possess better mechanical properties they may find applications in orthopedic fields. Since the raw materials used originate from waste, this bone implant would be profitable compared to conventional bone implant. MTT assay performed under different exposure conditions demonstrated the non-cytotoxic behavior of composites.

\section{Conflict of Interest Statement}

The authors of this manuscript have no conflicts of interest related to the content of the study. 


\section{Acknowledgements}

R. Senthil acknowledges the funding support granted by the Science and Engineering Research Board, Department of Science and Technology, (PDF/2015/00063) India.

\section{References}

[1] Senthil R, Vedakumari SW, Hemalatha T, Sumathi V, Gobi N, Sastry TP, New Approaches for the Effective Utilization of Fish Skin Wastes of Aluterus monoceros, $J$ Earth Environ Health Sci, 2: 50-5, 2016.

[2] Jayathilakan K, Sultana K, Radhakrishna K, Bawa AS, Utilization of byproducts and waste materials from meat, poultry and fish processing industries: a review, $J$ Food $S c i$ Technol. 49: 278-293, 2012.

[3] Sankar S, Sekar S, Mohan R, Sunita R, Sundaraseelan J, Sastry TP, Preparation and partial characterization of collagen sheet from fish (Lates calcarifer) scales, Int J Biol Macromol, 42: 6-9, 2008.

[4] Arvanitoyannis I, Kassaveti A, Fish industry waste: Treatments, environmental impacts, current and potential uses, Int J Food Sci Technol, 43: 726-45, 2007.

[5] Noorjahan SE, Sastry TP, Physiologically Clotted FibrinCalcined Bone Composite-A Possible Bone Graft Substitute, J Biomed Mater Res B, 75B: 343-350, 2005.

[6] Sundaraseelan J, Sastry TP, Fabrication of a Biomimetic Compound Containing Nano Hydroxyapatite-Demineralised Bone Matrix, J Biomed Nanotechnol, 3: 1-5, 2007.

[7] Manjubala I, Sivakumar M, Sureshkumar RV, Sastry TP, Bioactivity and osseointegration study of calcium phosphate ceramic of different chemical composition, J Biomed Mater Res, 63: 200-208, 2002.

[8] Saffar JF, Colombier ML, Datenville R, Bone formation in tricalcium phosphate filled periodontal infrabony lesions. Histological observations in humans, J Periodontol, 61: 209216, 1990.

[9] Amit Kumar N, Hydroxyapatite Synthesis Methodologies: An Overview, Int J Chem Tech Res, 2: 903-907, 2010.

[10] Guizzardi S, Montanari C, Migliaccio S, Strocchi R, Solmi R, Martin D, Ruggeri A, Qualitative assessment of natural apatite in vitro and in vivo, J Biomed Mater Res A, 53: 227-234, 2000.

[11] Kang YH, Kim HM, Byun JH, KimUK, Sung IY, Cho YC, Park BW, Stability of simultaneously placed dental implants with autologous bone grafts harvested from the iliac crest or intraoral jaw bone, BMC Oral Health, 15: 3-11, 2015.

[12] Gruskin E, Doll BA, William Futrell F, Schmitz JP, Hollinger JO, Demineralized bone matrix in bone repair: History and use, Adv Drug Deliv Rev, 64: 1063-1077, 2012.

[13] Saraswathy G, Pal S, Rose C, Sastry TP, A novel bioinorganic bone implant containing deglued bone, chitosan and gelatin, Bull Mater Sci, 24: 415-420, 2001.

[14] Krithiga G, Antaryami J, Selvamani P, Sastry TP, In vitro study on biomineralization of biphasic calcium phosphate biocomposite crosslinked with hydrolysable tannins of Terminalia chebula, Bull Mater Sci, 34: 589-594, 2011.
[15] Krithiga G, Kumar BS, Divya SM, Sastry TP, Influence of mineral phase in mineralization of a biocomposite containing chitosan, demineralized bone matrix and bone ash-in vitro study, Bull Mater Sci, 37: 729-733, 2014.

[16] Zhang R, Ma PX, Poly( $\alpha$-hydroxyl acids)/hydroxyapatite porous composites for bone-tissue engineering. I. Preparation and morphology, J Biomed Mater Res, 44: 446-455, 1999.

[17] Jitendra P, Rajam AM, Kalaivani T, Mandal AB, Rose C, Collagen based silver nanoparticles for biological applications, Appl Mater Interfaces, 5: 7291-7298, 2013.

[18] Jianguo L, Haihong L, Malena S, Characterization of calcium phosphates precipitated from simulated body fluid of different buffering capacities, Biomaterials, 18: 743-747, 1997.

[19] Arockianathan PM, Sekar S, Kumaran B, Sastry TP, Preparation, characterization and evaluation of biocomposite films containing chitosan and sago starch impregnated with silver nanoparticles, Int J Biol Macromol, 50: 939-946, 2012.

[20] Ucker BET, Cottel CM, Auyering RCV, Spector M, Nicollas $\mathrm{GH}$, Pre-conditioning and dual constant composition dissolution kinetics of pulsed laser deposited hydroxyapatite thin films on silicon substrates, Biomaterials, 17: 631-637, 1996.

[21] Plepis AMG, Goissis G, Das-Gupta DK, Dielectric and pyroelectric characterization of anionic and native collagen, Polym Eng Sci, 36: 2932-2938, 1996.

[22] Das D, Zhang Z, Winkler T, Mour M, Gunter GI, Morlock $\mathrm{MM}$, Machens HG, Schilling AF, Bioresorption and Degradation of Biomaterials, Adv Biochem Engin Biotech, 126: 317-333, 2011.

[23] Dohan Ehrenfest DM, Coelho PG, Kang BS, Sul YT, Albrektsson $\mathrm{T}$, Classification of osseointegrated implant surfaces: materials, chemistry and topography, Trend Biotech, 28: 198-206, 2010.

[24] Sopyan I, Melb M, Rameshc S, Khalidd KA, Porous hydroxyapatite for artificial bone applications, Sci Tech $A d v$ Mater, 8: 116-123, 2007.

[25] Boskey AL, Bone composition: relationship to bone fragility and antiosteoporotic drug effects, Nature: Bone K Ey Reports, 44: 7 1-11, 2013.

[26] Mbarki M, Sharrock P, Fiallo M, EIFeki H, Hydroxyapatite bioceramic with large porosity, Mater Sci Eng, 76: 985-990, 2017.

[27] Liu, FH, Fabrication of Bioceramic Bone Scaffolds for Tissue Engineering, J Mater Eng Perform, 23: 3762-3769, 2014.

[28] Greeshma T, Giridhar M, Bikramjit B, In vitro/In vivo assessment and mechanisms of toxicity of bioceramic materials and its wear particulates, RSC Adv, 4: 12763-12781, 2014.

[29] Senthil R, Nivedita P, Hemalatha T, Vedakumari WS, Sastry TP, A possible wound dressing material from marine food waste, Int. J. Artif. Organs, 39: 509-517, 2016.

[30] Nudelman F, Pieterse K, George A, Bomans PH, Friedrich H, Brylka LJ, Hilbers PA, de With G, Sommerdijk NA, The role of collagen in bone apatite formation in the presence of hydroxyapatite nucleation inhibitors, Nature Materials,: 1004-1009, 2013. 